\title{
FACTORS AFFECTING THE REVERSAL OF GENDER DISPARITY IN HIGHER EDUCATION INSTITUTIONS (HEIS): A SYSTEMATIC REVIEW
}

\section{Zakee Saadat}

Department of Journalism, Faculty of Arts and Social Science University Tunku Abdul Rahman (UTAR), Kampar Malaysia zakeesaadat@1utar.my

\section{Sultana Alam*}

Department of Journalism, Faculty of Arts and Social Science University Tunku Abdul Rahman (UTAR), Kampar Malaysia sultana@utar.edu.my

*Corresponding author's Email: sultana@utar.edu.my 


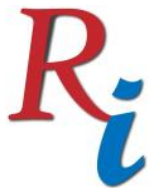

\section{Asia Proceedings of Social Sciences \\ (APSS) \\ www.readersinsight.net/APSS}

\section{A b s t r a c t}

The commencement of higher education has observed male dominance for a very long time. However, over the past two decades, this situation has reversed. Male students are considered as a new minority in higher education institutions. This phenomenon is prominently observed in industrialized countries of the world and termed as 'changing gender disparity' in higher education institutions. Countries like the U.K., USA, Netherland, Germany and France are noticeable examples of the changing gender disparity. According to the U.S. Department of Education, the year 2019 observed a significant increase in female students' participation (more than 56\%), whereas male students have deteriorating participation in higher education institutions. The European countries tend to have a similar trend whereby female students are outnumbering male students in terms of enrollment in higher education institutions. These changing gender disparity measures could result in social imbalance, causing severe social problems. For this purpose, it is crucial to determine the factors that caused the reversal of gender disparity in higher education institutions. In this context, this paper systematically reviews the literature on the factors causing less male participation in higher education institutions. The paper has adopted the PRISMA protocol for Systematic Literature Review (SLR). The paper has identified research papers that have attempted to identify the factors affecting less male participation in higher education. Furthermore, the paper has also highlighted the factors which have been identified by previous peer reviewed studies. The findings of this paper can be a potential source of information for further studying the issue related to the reversal of gender disparity, thus contributing significantly towards the relevant literature.

\section{Research High I ight s}

- This research paper systematically reviews the existing literature on the reversal of gender disparity in higher education institutions.

- To identify the factors affecting gender disparity in higher education institutions by using the PRISMA technique.

- To discuss the factors that are causing gender disparity in term of less male participation in a higher education institution.

- The study emphasizes the importance of conducting more research to address the reversal of gender disparity in higher education institutions. 


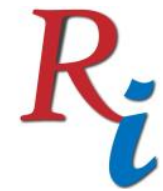

\section{Asia Proceedings of Social Sciences}

(APSS)

www.readersinsight.net/APSS

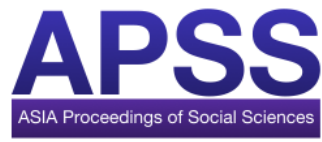

\section{Graphical A bstract}

\section{Process Flow of Systematic Review}
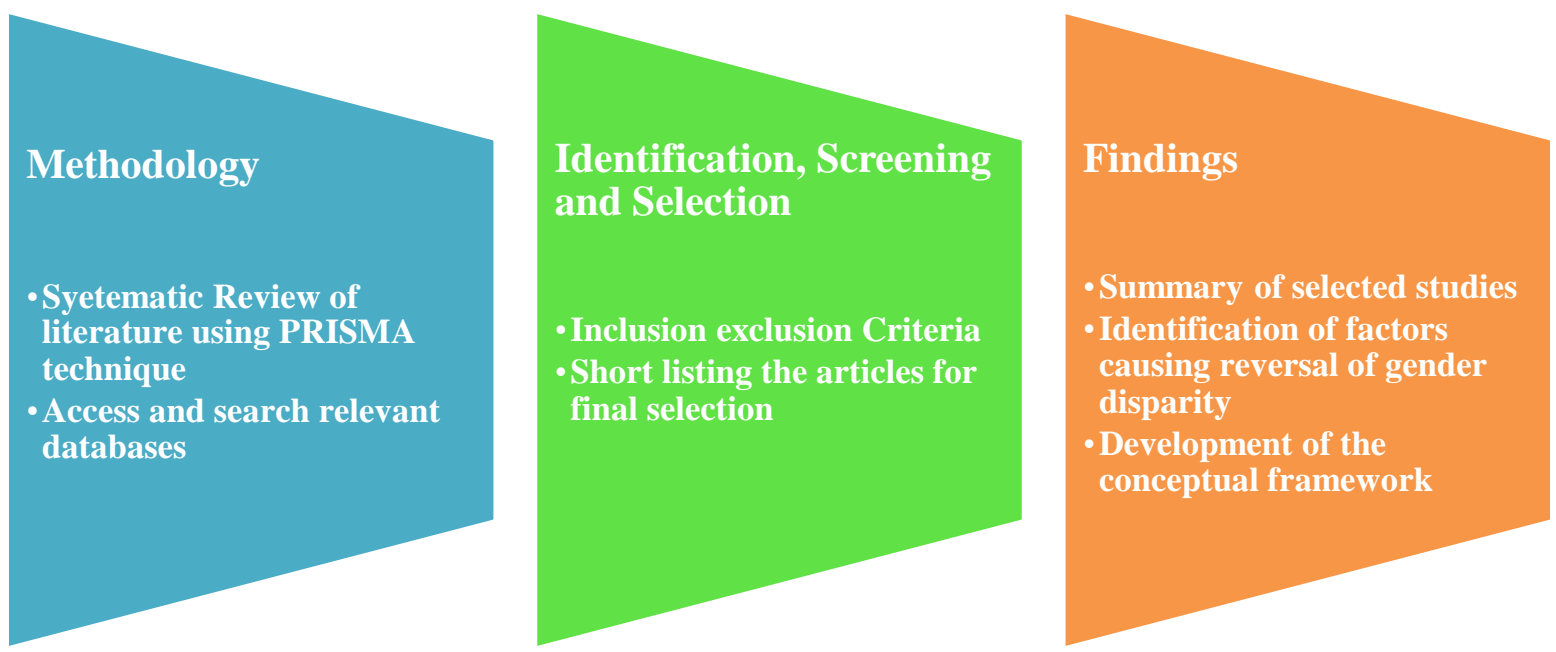

Conceptual Framework of Factors Affecting the Pursuit of Higher Education for Male Students

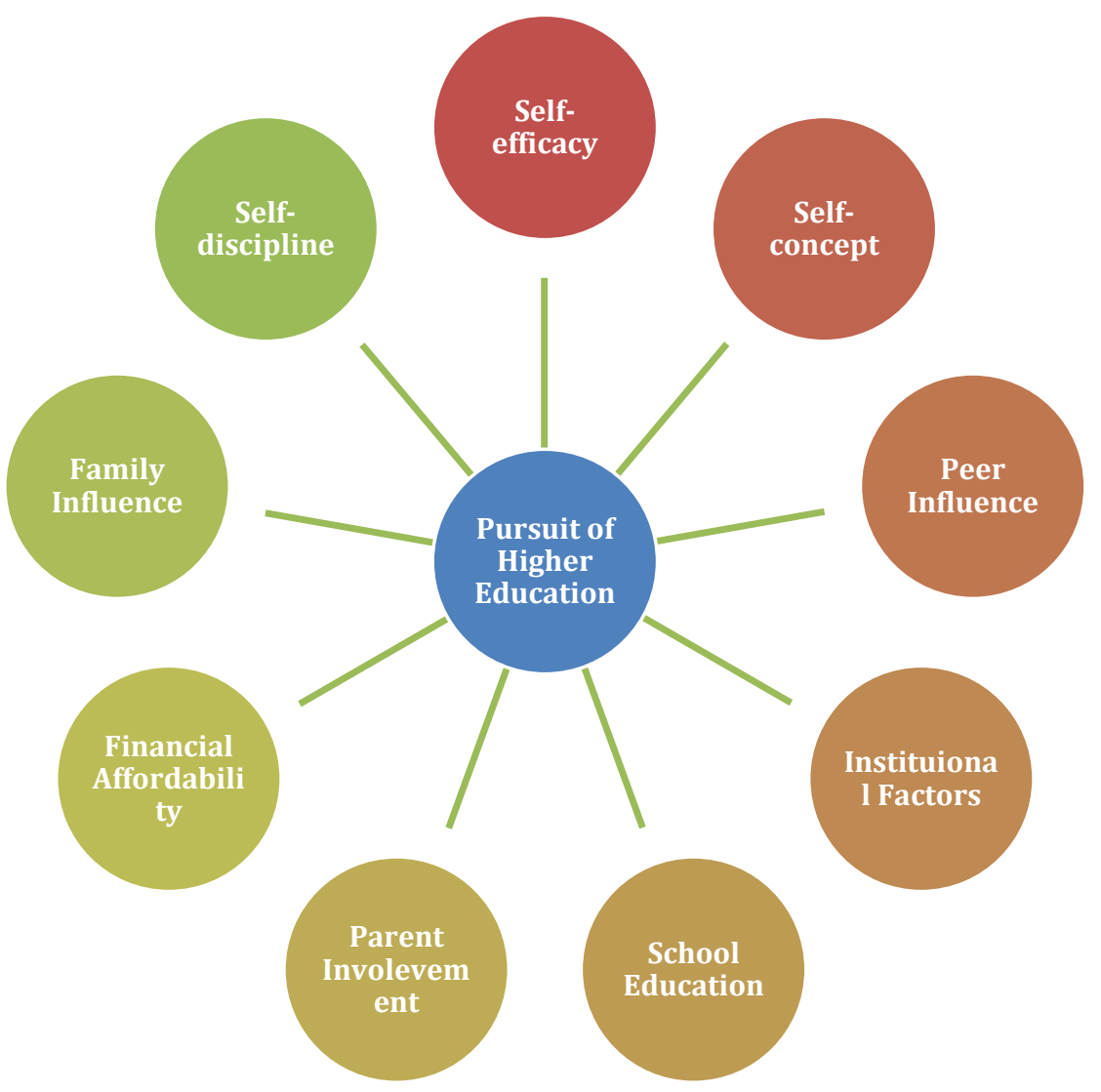

Copyright (C) 2020 Authors. This is an open access article distributed under the Creative Commons Attribution License, which permits unrestricted use, distribution, and reproduction in any medium, provided the original work is properly cited. 


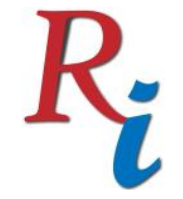

Asia Proceedings of Social Sciences

(APSS)

www.readersinsight.net/APSS

\section{Research Objectives}

The present research aims to provide a comprehensive depiction of the literature on factors affecting less male participation in higher education institutions.

The objectives of this research are the following:

- To review the relevant literature addressing gender disparity in terms of fewer male students participating in higher education institutions.

- To identify factors that affect male participation in pursuit of higher education institutions.

- To develop the conceptual model based on the factors affecting gender disparity in higher education institutions.

\section{Methodology}

This study aims to conduct a systematic review of literature on the factors causing a reversal of gender disparity in higher education institutions. For this purpose, the PRISMA (Preferred Reporting Items for Systematic reviews and Meta-Analysis) (Moher et al., 2015) technique is used to undertake the systematic review. The PRISMA is a well-established systematic review technique used in extensive literature work. This technique includes a series of steps for achieving the research objectives. The steps in this technique involve determining the search string, execution of search, screening, eligibility and inclusion criteria for a systematic approach towards relevant review.

\section{Results}

This paper attempts to conduct a systematic review of the literature for identifying the factors affecting gender disparity in higher education institutions. The last two decades have observed a reversal of gender disparity in higher education institutions. This phenomenon is not limited to developed countries; some of the developing countries are also getting into this situation. The focus of this study is to address less male participation in higher education institutions. The systematic review technique showed that there is inadequate literature available while discussing less male participation in higher education institutions. This limited literature came up as the greatest challenge in conducting the review of the literature. Whereas the systematic review, approach ended up concluding potential factors causing less male participation in higher education institutions. The factors include self-efficacy, self-concept, self-discipline, academic performance, role model, family influence, peer influence, financial affordability, financial support, school education, teacher influence, discipline and institutional factors and government policies.

Copyright (C) 2020 Authors. This is an open access article distributed under the Creative Commons Attribution License, which permits unrestricted use, distribution, and reproduction in any medium, provided the original work is properly cited. 


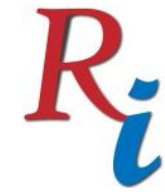

\section{Asia Proceedings of Social Sciences}

(APSS)

www.readersinsight.net/APSS

In addition to identification, this study has also highlighted the factors which are crucial and significantly affect less male participation in higher education institutions. Based on these identified factors, a conceptual framework is developed to understand the structure of results.

\section{Findings}

This research work has comprehensively reviewed the existing literature on gender disparity with special focus on less male participation in higher education institutions. Relatively limited literature is available discussing male disparity in higher education institutions globally. A conceptual framework has been devised to understand better the factors that affect the pursuit of higher education for male students. These factors need to be studied comprehensively to produce consistent and generalizable results for addressing this issue in higher education.

\section{Acknowledgement}

This research work is supported by Fundamental Research Grant Scheme (FRGS). We would like to express our sincere gratitude to Ministry of Higher Education Malaysia providing us financial support to carry out this research.

\section{References}

Moher, D., Shamseer, L., Clarke, M., Ghersi, D., Liberati, A., Petticrew, M., Shekelle, P., Stewart, L.A., 2015. Preferred reporting items for systematic review and metaanalysis protocols (PRISMA-P) 2015 statement. Syst. Rev. 4, 1. https://doi.org/10.1186/2046-4053-4-1

\section{Author's Biography}

Zakee Saadat is a doctoral student at the Department of Journalism, Faculty of Arts and Social Science, University Tunku Abdul Rahman (UTAR), Kampar. He has completed his Bachelor and Master's in Philosophy majoring in Government and Public Policy from National Defence University, Islamabad, Pakistan. Presently he is focusing on the research areas of gender disparity and higher education.

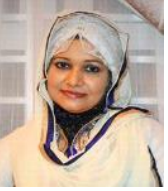

Dr M Sultana Alam is currently working as an assistant professor in the Department of Journalism, Faculty of Arts and Social Science, Universiti Tunku Abdul Rahman (UTAR). She received her Bachelor's and master's degree from the

University of Rajshahi, Bangladesh. She enrolled as a full-time candidate for the PhD program in the field of Community Development, Universiti Putra Malaysia (UPM), in November 2003. She completed her PhD. April 2006. She has published the number of articles in the refereed journals. Presently, she is focusing her research on women, STEM education, gender disparity, marriage and family. 